\author{
Andrés Maximiliano Tello \\ Universidad de Playa Ancha \\ andres.tello@upla.cl
}

\title{
“Otro fin de mundo es posible". Revuelta y anarchivismo
}

\section{"Another End of the World is Possible". Revolt and Anarchivism}

\section{Resumen}

Este texto propone algunas líneas de problematización sobre el vínculo entre anarchivismo y revuelta, a la luz de los acontecimientos desatados en Chile durante los últimos meses. Para ello, se parte asumiendo una noción no convencional del archivo (Foucault, Derrida), entendido aquí como máquina social (Deleuze y Guattari) que se encarga de establecer la organización jerárquica de los registros de los cuerpos en la sociedad. Poniendo especial énfasis en el archivo mediático e informacional, se ahonda aquí en las formas en que la máquina social de archivo ha sido complementaria al orden social instaurado por el gobierno neoliberal durante las últimas décadas. Luego, se analiza cómo la emergencia de la revuelta desata al mismo tiempo la proliferación de máquinas anarchivistas, es decir, de cuerpos y tecnologías que desestabilizan el archivo que soporta el orden neoliberal.

Palabras clave: Revuelta, anarchivismo, orden neoliberal.

\begin{abstract}
This text proposes some lines of problematization on the link between anarchivism and revolt, in light of the events unleashed in Chile during the last months. To do this, we start by assuming an unconventional notion of the archive (Foucault, Derrida), understood here as a social machine (Deleuze and Guattari) that is responsible for establishing the hierarchical organization of the records of bodies in society. With special emphasis on the media and information archives, we delve into the ways in which the social archive machine has been complementary to the social order established by the neoliberal government during the last decades. Then, we analyze how the emergence of the revolt unleashes at the same time the proliferation of anarchivist machines, that is, bodies and technologies that destabilize the archive that supports the neoliberal order.
\end{abstract}

Keywords: Revolt, Anarchivism, Neoliberal Order.

\section{Acabar con el mundo}

En la revuelta se juega siempre el alzamiento general contra toda forma de dominación. Cada uno de sus múltiples enfrentamientos, choques y maniobras, puede convertirse en la última jugada para la destitución de un gobierno o la transformación radical de un sistema. Toda revuelta también puede ser sofocada. De cualquier manera, la revuelta provoca una apertura 


\section{Andrés Maximiliano Tello}

insospechada, una desgarradura en el horizonte de aquello que era concebido como posible, y por lo mismo, en medio de la revuelta, cada afecto y oscilación de los cuerpos insurrectos tiene la potencia para destruir el ordenamiento del mundo que les ha sido impuesto. Precisamente por eso, la revuelta siempre tiene un germen anarchivista. Son muchas las dimensiones que están implicadas en la emergencia de toda revuelta, aunque una fundamental es la desestabilización del amplio control de las huellas registradas sobre la superficie social (desde la ficha policial hasta los algoritmos de reconocimiento facial). En otras palabras, toda revuelta perturba al archivo entendido como "máquina social" (Deleuze y Guattari, 1998) que establece la clasificación y disposición jerárquica de los múltiples registros de los cuerpos y sus huellas sobre la superficie de inscripción que llamamos realidad (Tello, 2018). Esto ya nos los había advertido Foucault, al sostener que el archivo no se refiere al "gran libro mítico de la historia" sino más bien el "espesor de las prácticas discursivas, sistemas que instauran los enunciados como acontecimientos (con sus condiciones y su dominio de aparición) y cosas (comportando su posibilidad y su campo de utilización)" (Foucault 2008: 169). Si la revuelta es capaz de acabar con el orden del mundo en el que irrumpe es porque, justamente, trastorna la organización de su archivo, es decir, perturba el orden instaurado en una sociedad y su determinación acerca de lo posible: aquello que es posible decir y sentir, la delimitación de los dichos y los hechos, de las actas y los actos, en definitiva, de los regímenes discursivos y sensoriales registrados en un momento específico.

Las revueltas que atraviesan hoy el mundo, y particularmente aquella que estalla en Chile el 18 de Octubre de 2019, pueden describirse entonces a partir de una profunda desestabilización del orden neoliberal, asumido como único mundo posible, y de la máquina social del archivo que su instauración supone. En lo que sigue, proponemos entonces algunos apuntes para una necesaria problematización del vínculo sedicioso entre la revuelta y lo que en otro lugar hemos denominado también como anarchivismo (Tello, 2018), es decir, entre el movimiento popular insurreccional y la desestabilización del archivo discursivo y sensorial de una sociedad.

\section{El orden neoliberal}

Foucault fue uno de los primeros en criticar radicalmente el orden del discurso neoliberal, sus diferentes prácticas de gobierno y sus procedimientos complementarios. Su afamado curso en el Collège de France dictado entre 1978-1979, Nacimiento de la biopolítica, que analiza los textos fundacionales del neoliberalismo como marco de desarrollo de un nuevo arte de gobernar, 


\section{Andrés Maximiliano Tello}

se imparte casi simultáneamente con las políticas económicas de shock que los Chicago Boys implementaron durante los primeros años de la dictadura chilena. Pero el aporte sustantivo de la crítica de Foucault radica en que, desde su mirada, el discurso del neoliberalismo y sus dispositivos de saber/poder no pueden circunscribirse solo a la aplicación de un conjunto de medidas ministeriales, ni tampoco reducirse a una ideología sobre el funcionamiento particular de un sistema económico. Lejos de esto, el neoliberalismo operaría más bien como una compleja "racionalidad de gobierno" que generaliza la forma empresa en el conjunto de la sociedad, convirtiendo al mercado en un principio de gestión para las intervenciones gubernamentales y en un principio de inteligibilidad para los comportamientos individuales (Foucault, 2009). En otras palabras, el neoliberalismo remite a una racionalidad de gobierno que "tiene como característica principal la generalización de la competencia como norma de conducta y de la empresa como modelo de subjetivación" (Dardot y Laval, 2013; 15). Por lo tanto, los registros de esta racionalidad de gobierno no se agotan en el caudal de informes, documentos y recomendaciones de ajustes estructurales impresos en las instituciones internacionales promotoras del libre mercado como el Grupo Banco Mundial o el Fondo Monetario Internacional, ni tampoco en las directrices que atraviesan el diseño de las políticas estatales a nivel nacional, pues filtran también el conjunto de saberes hegemónicos (económicos, jurídicos, médicos, estadísticos, científicos, etc.) y la panoplia de producciones culturales que promueven los principios de la competencia y la subjetividad empresarial. Estos últimos han sido los principios moduladores de los comportamientos y los rendimientos de los cuerpos en sus distintas actividades vitales, asegurando así la intensificación constante de sus modos de explotación. El objetivo del gobierno neoliberal no es otro sino el de la inmersión de la propia vida, sus manifestaciones y proyecciones, en la grilla del mercado.

En ese sentido, el archivo del orden neoliberal puede entenderse, en primer lugar, vinculado al establecimiento en nuestra sociedad de lo que Foucault denomina como un "régimen de verdad", es decir, a "la articulación de una serie de prácticas de cierto tipo de discurso que, por un lado, lo constituye como un conjunto ligado por un lazo inteligible y, por otro, legisla y puede legislar sobre esas prácticas en términos de verdad o falsedad" (Foucault 2009; 31). La operación de este "régimen de verdad" en el neoliberalismo no solo queda clara en el vasto corpus documental de sus precursores teóricos de mediados del siglo XX -analizado por Foucault precisamente en Nacimiento de la biopolítica- sino que además se reafirma más tarde con el ya 


\section{Andrés Maximiliano Tello}

clásico slogan político popularizado por Margaret Tatcher, y que retoman hasta el día de hoy todos los apologistas de la sociedad de mercado: "There is no alternative". De ese modo el neoliberalismo forma un complejo dispositivo de saber-poder que marca la distinción entre lo real y lo falso, registrando en lo real lo inexistente.

"No hay alternativa" es mucho más que un slogan, es la impronta medular del régimen de verdad neoliberal como intento de perpetuación e intensificación de los variados modos de explotación y devastación capitalista que operan hoy a nivel planetario. Es este también el enunciado base de lo que Mark Fisher ha denominado con agudeza como "realismo capitalista", es decir, "la idea muy difundida de que el capitalismo no solo es el único sistema económico viable, sino que es imposible incluso imaginarle una alternativa" (Fisher 2018; 22). A contracorriente de esta idea, la rebelión popular inscribe en los muros de Santiago de Chile la consigna: "Otro fin de mundo es posible!", otro que no sea precisamente aquel al que nos arrastra la catástrofe medioambiental provocada por el capitalismo, sino más bien el de la declinación del orden del mundo que ha construido esa racionalidad de gobierno autoproclamada como posibilidad única.

El archivo del orden neoliberal se articula también en los enunciados y prácticas de los registros de los aparatos jurídicos y el orden constitucional, que en el caso chileno se hace aún más evidente con la vigencia de la Constitución política de 1980 -instaurada por la dictadura cívico-militar y contra la cual la revuelta también se alza hoy-, pues este documento plasma "un modelo de sociedad funcional a la acumulación de poder en clave neoliberal" (Bassa, 2019). En este sentido, no es de extrañar que los defensores del archivo del orden neoliberal sean al mismo tiempo los defensores de la Constitución de Pinochet. Ahora bien, considerando el régimen de verdad que atraviesa los discursos y las prácticas económicas, políticas y jurídicas de nuestra sociedad, podría sostenerse que el archivo es una máquina social que remite siempre al doble principio albergado en la noción de arkhé, tal cual lo ha subrayado Jacques Derrida (1997), es decir, establece un origen del mundo (un principio histórico, físico u ontológico, que en el caso del neoliberalismo se expresa en la generalización de la competencia como principio de la conducta humana y del mercado como supuesto sustrato ontológico a partir del cual concebir la sociedad) y un mandato sobre el ordenamiento del conjunto de registros que resguarda como principio nomológico, es decir, como el mandato que se impone sobre la extensa producción de sus enunciados y sus prácticas asociadas, que plasma al mismo tiempo la ley (y su violencia 


\section{Andrés Maximiliano Tello}

arcóntica, o como diría Weber, el monopolio "legítimo" de la violencia) que se hace valer a partir de ellos. Así, habría que tomar en serio, tal cual lo advierte la arqueología del mandato/orden realizada por Giorgio Agamben, el hecho de que "el comienzo en nuestra cultura no es un mero inicio que luego desaparece en lo que sigue; por el contrario, el origen nunca cesa de comenzar, es decir, nunca cesa de gobernar y mandar lo que ha iniciado" (Agamben 2012; 51). El principio neoliberal de una sociedad de mercado y el mandato jurídico-policial con la que su orden se mantiene parece entonces no tener contrapesos mientras la máquina social de archivo organiza los registros del cuerpo social. De ahí pues que la revuelta chilena de Octubre sea también una rebelión contra el archivo construido a partir de esos principios del orden neoliberal, esto es, una fuerza destituyente del arkhé que atraviesa los discursos y las prácticas que hasta ahora habían sido dominantes en nuestra sociedad.

Con todo, el orden neoliberal del archivo se aprecia de manera más evidente aún en el funcionamiento del sistema mediático e informacional que su forma de gobierno promueve. Este también había sido advertido por Foucault ya hacia fines de los años setenta, mientras desarrollaba precisamente su curso sobre la gubernamentalidad neoliberal. En una breve intervención pública de 1978, el pensador francés realiza un diagnóstico sobre la configuración de un "nuevo orden social", cuya economía de poder y tecnologías securitarias serían radicalmente distintas a los dispositivos biopolíticos de encierro y normalización que caracterizaban a las viejas sociedades disciplinarias (Foucault 1991; 163-166). Se trata, por cierto, de la misma hipótesis que Gilles Deleuze reforzará más tarde, en 1990, en su conocido Post-scriptum sobre la sociedades de control, donde detalla algunas características de este "nuevo régimen de dominación" -que hoy llamamos neoliberalismo-, entre las que destaca su capacidad tecnológica para producir "una modulación universal" (Deleuze 1999; 284-285). Ahora bien, en 1978, por su parte, Foucault planteaba que la emergencia de esta nueva forma de control social estaría impulsada principalmente por una crisis progresiva del Estado Benefactor, que lo obligaría a economizar en los diferentes mecanismos de intervención social e impulsaría un nuevo diseño de los dispositivos securitarios en el marco de la gubernamentalidad neoliberal en ciernes.

La nueva economía del orden neoliberal recurriría entonces a una vasta máquina de archivo mediático-informacional que, según Foucault, reuniría al menos cuatro características fundamentales: 1) La localización de un cierto número de "zonas vulnerables" o "zonas de 


\section{Andrés Maximiliano Tello}

peligrosidad" en el cuerpo social, donde se focalizarían los mecanismos de vigilancia y el endurecimiento de las penas; 2) Una flexibilización de los controles cotidianos, que tienden a considerar ciertos márgenes de tolerancia, un porcentaje de delitos que adquieren un carácter regulador; 3) La generación de un "sistema de información general" que es, sostiene Foucault, indispensable para el marcaje de las zonas vulnerables, y que por lo tanto ya no tendría como objetivo principal la vigilancia de cada individuo, sino la intervención frente a la emergencia de cualquier peligro o contraconducta en el cuerpo social; y 4) La constitución del consenso, que pasaría por todos esos controles y regulaciones realizadas a través de los medios de comunicación, que permiten que el poder se autoengendre y autogestione "a partir de su propios agentes" (Foucault 1991; 165-166), que serían los individuos que asumen dichos consensos. Estos cuatros ejes de la nueva economía informacional del orden neoliberal han sido desplegados plenamente en el transcurso de la postdictadura chilena. En lo que sigue, nos referiremos a la configuración de la máquina de archivo mediática e informacional instaurada en Chile y en cómo la revuelta en curso contra el gobierno neoliberal de la vida se traduce también en su posible fracaso.

\section{Control informacional y máquinas anarchivistas}

El 25 de Octubre de 2019, aún bajo el estado de excepción y el despliegue de la represión militar-policial con que el gobierno de Piñera buscaba infructuosamente sofocar la rebelión popular en la calles del país, se hizo pública una carta del director de la Federación de Trabajadores de Canales de Televisión (FETRA), Iván Mezzano, quien acusaba al presidente de la República y al ministro del Interior, Andrés Chadwick, de haberse reunido en el palacio de gobierno con todos los directores ejecutivos de los medios televisivos con el objetivo de intervenir en la definición de sus líneas editoriales y de prensa, delimitando de ese modo el tipo de información con que los canales de televisión y sus noticiarios cubrirían las movilizaciones sociales en curso. Esta coordinación para el establecimiento de agenda entre el Ministerio del Interior y los agentes empresariales del mercado televisivo, no solo intentaba sofocar la amplificación nacional e internacional de la revuelta así como invisibilizar su violenta represión por parte del gobierno, sino que además sepultaba todo principio de pluralismo, libertad de expresión y cualquier atisbo de democracia, en un país donde la represión policial-militar y las violaciones a los derechos humanos no son la excepción sino la regla. Asimismo, semejante 


\section{Andrés Maximiliano Tello}

medida de control sobre el archivo mediático, sobre los filtros y los marcos de sus informaciones, no puede leerse únicamente como un procedimiento gubernamental aislado o de coyuntura, sino que debe ser entendida como una operación que es parte de la amplia economía informacional desplegada durante toda la postdictadura, es decir, siendo parte constitutiva del "consenso" mediático que caracteriza uno de los ejes del nuevo orden neoliberal y su archivo informacional (Foucault, 1991).

De hecho, la constitución de dicho consenso mediático es parte fundamental del pacto entre élites políticas y económicas, cuya expresión puede rastrearse en los mismos contenidos de los medios de comunicación masivos, tal como lo ha demostrado Ximena Orchard (2019) con su investigación sobre los actores políticos considerados en los principales medios de prensa escrita nacional (El mercurio, La Tercera y La Segunda) desde 1990 hasta 2019. Allí se indica que, en todo este periodo, el $85 \%$ de los actores considerados en la sección política de la prensa escrita han sido miembros de la política institucional, y las voces más recurrentes son las de los representantes del duopolio político -la Nueva Mayoría y Chile Vamos-, mientras que los agentes de la sociedad civil apenas tienen una aparición marginal. La investigadora plantea entonces que "esta homogeneidad histórica de las élites políticas" en los medios de prensa se traduce en la "capacidad ampliada de estos grupos para definir qué es lo relevante y cuándo en el espacio público" (Orchard, 2019), excluyendo así las posibilidades del disenso en los debates que cubren estos medios de comunicación masivos. Por supuesto, este consenso entre élites políticas es también un consenso sobre el orden social establecido con el sector mediático y, por lo tanto, con las élites económicas, propietarias de los principales medios de comunicación nacionales. La alta concentración de los medios y las infraestructuras tecnológicas en Chile está encabezada por el conocido duopolio de la prensa escrita, donde las empresas El Mercurio Sociedad Anónima y el Consorcio Periodístico Sociedad Anónima (COPESA), propiedad de los grupos Edwards y Saeih respectivamente, concentran casi el 98\% del sector -extendiéndose rápidamente también en los medios digitales-, y donde cuatro operadores de televisión abierta (TVN, MEGA, C13 y CHV) dominan el $91 \%$ de la audiencia total, con los grupos Luksic y Solari entre sus dueños. Los conglomerados comunicacionales del nuevo orden neoliberal son entonces parte fundamental del pacto oligárquico entre las élites políticas y empresariales de nuestro país, cuyo consenso determina la organización del archivo mediático e informacional. 


\section{Andrés Maximiliano Tello}

La máquina de archivo del orden neoliberal no se restringe solamente a la concentración de los medios de comunicación y su establecimiento de agenda. Se complementa, por cierto, con las nuevas tecnologías digitales de control utilizadas por la clase política y los aparatos policiales. En el primer caso, un ejemplo paradigmático es la empresa chilena de Big Data, Instagis, emuladora de la famosa Cambridge Analytica, que se convirtió en la principal herramienta de los partidos políticos de la derecha pinochetista para optimizar sus estrategias de gobierno y explotación de la población a través de las plataformas digitales. El negocio de Instagis se basa en el monitoreo de los contenidos que nosotros mismos entregamos en Twitter, Facebook o Instagram, que luego son cruzados con los datos de nuestro domicilio y número de identificación, para generar así un mapa geo-referenciado de información específica como, por ejemplo, la inclinación política de cada usuario (CIPER, 2018). El procesamiento de estos datos masivos le ha permitido a los defensores del modelo neoliberal chileno refinar sus campañas electorales, mediante la elaboración de distintos perfiles políticos del universo de usuarios en distintas redes sociales, que tienen como objetivo la identificación de las características de sus potenciales votantes y el diseño de mensajes ajustados para cada grupo específico. Así, el orden neoliberal demuestra que el monopolio de las infraestructuras tecnológicas por parte de las élites políticas y empresariales tiende a coincidir también con el monopolio del uso de los datos masivos.

En el caso de las máquinas de archivo del aparato policial, su composición no solo pasa por los archivos de la Dirección de Inteligencia de Carabineros -que sabemos, gracias a las filtraciones de documentos llevadas a cabo por hackers en medio de la revuelta, tenían como principales "blanco de interés" a dirigentes y organizaciones sociales, y no precisamente a carteles criminales (Sepúlveda, 2019) - sino que además se expande en las numerosas cámaras de seguridad instaladas en nuestras ciudades y en programas como el Sistema de Automatización de Unidades Policiales (AUPOL), que genera datos sobre los delitos cometidos a lo largo del país y un mapa geo-referencial que permite también el uso de softwares "predictivos" del crimen, delimitando anticipadamente cuadrantes de alto riesgo. La implementación de estas tecnologías de ciber-seguridad no ha estado exenta de polémicas, aunque según sus promotores, estos programas informáticos asegurarían no solo una reducción en los porcentajes de delitos sino que además tenderían a economizar la inversión estatal en seguridad pública, optimizando así sus recursos. Sin embargo, como bien lo ha explicado Cathy O’Neil (2017), la frecuente inclusión de datos sobre "delitos menores" -como los de "alteración del orden público"- en los programas 


\section{Andrés Maximiliano Tello}

informáticos para la predicción del crimen, aumenta finalmente los patrullajes y los arrestos en los barrios más empobrecidos o en las zonas populares, creando así un "bucle de retroalimentación pernicioso" (O’Neil 2017; 110), pues la vigilancia policial en estos sectores va generando nuevos datos que "justifican" un mayor control sobre población que ha sido ya socialmente segregada, y ahora es re-estigmatizada mediante dispositivos informáticos. A todo lo anterior habría que sumar también el creciente monitoreo de redes sociales públicas y el uso de algoritmos de reconocimiento facial con fines persecutorios (La Mura, 2019), operaciones recurrentes de la máquina informacional con que los aparatos policiales intentan hoy asegurar el orden social del neoliberalismo.

No obstante, el despliegue de todos estos dispositivos ciber-securitarios y la progresiva concentración capitalista de las infraestructuras mediáticas por parte de las élites políticas y empresariales en ningún caso constituyen un orden imperecedero. Luego de Octubre de 2019 esto se hace evidente. El archivo informacional del orden neoliberal es desconfigurado por la revuelta, ya desde el mismo momento en que la arremetida feroz de los cuerpos y sus deseos se muestra como impredecible, no calculable para ningún programa informático de gobierno. Las multitudes insurrectas no solo se apropian de las calles, los muros y todos los espacios de reunión y experimentación colectiva que habían sido confinados por el orden neoliberal, sino que desmontan al mismo tiempo el control de los registros y los flujos informativos. Quienes forman parte de la revuelta transmutan los empleos convencionales de los cuerpos y sus artefactos suplementarios, de tal modo que todos los entornos técnicos son potencialmente modificados, convertidos en un nuevo campo de intervención cuando el movimiento insurreccional aparece en escena. Así, por ejemplo, el uso insurrecto de las tecnologías digitales ha sido una de las características de las revueltas que recorren hoy el mundo -desde Hong-Kong hasta Barcelona, pasando por el Líbano, Quito y otras tantas ciudades-, rebelión global que justamente desea acabar con ese mundo construido por el capitalismo.

La rebelión popular re-inventa usos subversivos de los aparatos disponibles (teléfonos móviles, plataformas digitales o tecnologías cotidianas más simples como un puntero láser, que puede convertirse en una forma eficaz de obstrucción de las aeronaves de vigilancia policial), para interrumpir los cercos mediáticos y franquear de un modo u otro los dispositivos gubernamentales que buscan modular la opinión pública e intensificar la explotación neoliberal de los cuerpos y los territorios en lucha. Las múltiples estrategias de reconversión y apropiación 


\section{Andrés Maximiliano Tello}

tecnológica se vuelven virales. Esto nos recuerda otra advertencia de Deleuze; a diferencia de las sociedades del viejo capitalismo industrial que veían su mayor amenaza en el sabotaje y la destrucción de la maquinaria, el peligro activo al que se enfrentan las sociedades de control contemporáneas, con el desarrollo de sus máquinas informáticas y computacionales, es más bien el de "la piratería y la inoculación de virus" (Deleuze 1999; 282). Mientras la función básica de estos últimos es propagarse mediante un software, alterando los sistemas informáticos, la reproducción exponencial de contenidos en redes sociales, conocida como viralización, tiene el potencial de perturbar también los dispositivos de la gubernamentalidad mediática. Al suprimir la distinción entre receptor y emisor, activando flujos irreductibles de producción, alteración y transmisión de contenidos, las tecnologías reticulares se convierten en un suplemento para la acción de medios alternativos y activistas digitales que viralizan contra-información en desmedro de todo control. Piénsese, por ejemplo, en las múltiples denuncias sobre violaciones a los derechos humanos realizadas durante el transcurso de la revuelta chilena, viralizadas por usuarios de redes sociales como Instagram o WhatsApp, que permitieron visibilizar la violencia de las fuerzas represivas del gobierno y vencer el dispositivo de miedo y silencio que el estado de excepción buscaba imponer en la población.

El peligro de la viralización para la sociedad de control reside además en que sus efectos desbordan incluso los activismos tradicionales y las militancias digitales de "expertos". Cualquier persona que es testigo de la violencia policial puede registrarla y denunciarla inmediatamente en sus redes sociales. Además, las tecnologías digitales y sus modos de viralización aceleran los diferentes procesos de organización colectiva y los mecanismos de coordinación de actividades online/offline de agrupaciones políticas heterogéneas. Estos procesos y mecanismos se vuelven no solo más inmediatos sino que también más flexibles, descentralizados y, en ocasiones, efímeros. Por lo tanto, a diferencia de las formas tradicionales de organización política, con estructuras jerárquicas e institucionales, la acción colectiva a la que dan soporte las tecnologías digitales y las redes sociales parece más bien adoptar la lógica del virus, aunque también la del anonimato, desafiando así los sistemas de control gubernamental.

Con las infraestructuras digitales la revuelta deviene rebelión global, pues multiplica el entusiasmo y el deseo de luchas que devienen innumerables, que erosionan toda frontera en los meandros de las redes, operando lo que Érik Bordeleau llama una "potencia desmultiplicadora del anonimato", es decir, maximizando la eficacia de las interrupciones políticas por medio de la 


\section{Andrés Maximiliano Tello}

disimulación de la identidad de las fuerzas disidentes (Bordeleau 2018; 12). Así, entre multiplicación y desmultiplicación, desde los y las capuchas de primera línea hasta Anonymous, las tecnologías digitales tienden a potenciar una productiva relación entre anonimato estratégico y acción colectiva insurgente. Desde hace al menos una década, con el desarrollo de la web 2.0, la expansión de los smartphones y la conexión inalámbrica, los antiguos flujos de disidencia viral se desterritorializan ahora irrigándose entre "multitudes conectadas", que "toman las plazas" y que:

"ya no son colectivos organizados que se vinculan entre sí formando redes activistas, sino que son esos 'cualquiera' que a título personal salen a las calles, se encuentran y construyen espacios de convivencia e interlocución inesperados" (Rovira 2017; 14).

En ese sentido, la revuelta es algo más que la alteración del orden público, trastorna la organización habitual de las tecnologías de registro del cuerpo social, la disposición de la máquina social del archivo. La revuelta, por lo tanto, es siempre una proliferación de máquinas anarchivistas (Tello, 2018) que transforman los regímenes sensoriales, las formas de visibilidad y enunciabilidad en un espacio tiempo determinado, es decir, provocan una alteración de los discursos y las prácticas no discursivas, de las posiciones, las funciones e identidades asignadas a los cuerpos y sus afectos. Este trastorno de la máquina social del archivo, conlleva aquello que Franco "Bifo" Berardi ha definido como una recombinación: modifica las relaciones entre diferentes elementos (técnicos, afectivos, estéticos e imaginarios), "de modo que se produzca un resultado semiótico y funcional distinto del que derivaba de la combinación precedente" (Berardi 2015; 177). Pero al mismo tiempo, la alteración producida por las máquinas anarchivistas que proliferan en la revuelta puede llegar a transformar los diagramas de poder, en el campo de fuerzas político, de una manera radical y prolongada en el tiempo, es decir, tiene el potencial de cambiar las propias relaciones de gobierno, no ya bajo las lógicas de la soberanía estatal o del doble principio del arkhé sino más bien de acuerdo con los procedimientos situados y contingentes de auto-gobierno territorial. En ese sentido, la proliferación de máquinas anarchivistas no solo interrumpe la máquina social del archivo en sus acoplamientos con el aparato estatal o la "axiomática capitalista" (Deleuze, 2017) sino que además puede desterritorializar los dispositivos de poder gubernamentales, desactivando su funcionamiento para 


\section{Andrés Maximiliano Tello}

ensamblar nuevos soportes comunes de auto-gobierno del espacio de inscripción de los afectos, los cuerpos y sus registros, generando simultáneamente nuevos modos de subjetivación política y tecnologías de re-distribución expansiva y una gestión colectiva de los recursos.

Los modos de subjetivación política concatenados en las máquinas anarchivistas que proliferan durante la revuelta implican un complejo ensamblaje de materialidades e intensidades, es decir, de tecnologías de registro, cuerpos y afectos que gatillan la invención de nuevos espacios y relaciones de auto-gobierno. La materialidad de esas máquinas anarchivistas se elabora en comunicados, panfletos, murales, periódicos, convocatorias, barricadas, afiches, consignas, cantos, fotografías, asambleas, videos, reuniones informativas, caravanas, bailes y perfomances. Esa materialidad de los ensamblajes maquínicos de la revuelta es, en cualquier caso, una materialidad no meramente empírica, sino que cargada de intensidades afectivas que son irreductibles al dato, que hacen que la supervivencia de sus huellas no sea nunca abreviable en la objetividad de los hechos. Menos aún, en los hechos que intentarán establecer los archivos policiales en caso de que el ordenamiento de los cuerpos y los corpus sea re-establecido. Al mismo tiempo, los ensamblajes de las máquinas anarchivistas pueden desarrollar formas de gobierno y auto-gestión que se materializan en la disposición de soportes comunes como los medios de comunicación comunitarios, desde la radio y la televisión hasta las redes WIFI comunales, así como también otros tipos de hardware e infraestructuras colectivas, como centros comunitarios, escuelas, talleres o fábricas re-apropiadas.

\section{A modo de conclusión: La revuelta como proliferación nomádica}

La revuelta debe distinguirse de la revolución, como bien lo ha subrayado Furio Jesi (2014), pues en esta última nos encontramos generalmente frente a un conjunto de acciones basadas en planes estratégicos de largo plazo que pretenden cambiar en el tiempo histórico un contexto social, político y económico determinado, mientras que en la emergencia de la revuelta opera más bien una suspensión del tiempo histórico (Jesi, 2014). A diferencia de la revolución, en la revuelta no hay un programa futuro, no se prepara el mañana, y quienes participan en ella se disuelven entre la muchedumbre sublevada, escapando de las instituciones del enemigo y encontrando un refugio colectivo en medio de la batalla. El movimiento insurreccional de la revuelta no está sumergido de ningún modo en el tiempo histórico, al contrario, implica una 


\section{Andrés Maximiliano Tello}

experiencia distinta del propio tiempo y espacio normalizados en la sociedad, pues su rasgo distintivo es la interrupción del transcurrir tranquilo o previsto de la historia. Sin embargo, lo problemático de la definición de la revuelta en Jesi, es que esta última aparece como una discontinuidad que puede luego fundirse en el curso normal del tiempo:

"cuando la revuelta ha pasado, independientemente de su resultado, cada uno vuelve a ser un individuo en una sociedad mejor, peor o igual a la de antes. Cuando termina el enfrentamiento (...), vuelven a comenzar las batallas cotidianas individuales" (Jesi 2014; 72).

Aquí puede entonces diferenciarse una concepción de la revuelta como interrupción de tiempo histórico de otra que la entiende más bien como proliferación de máquinas anarchivistas. Esta última no solo suspende el tiempo histórico o la normalización de la experiencia colectiva, sino que además incrementa e intensifica el despliegue anarchivista de un tipo de formaciones sociales o "máquinas nómadas" que siempre pre-existe en el cuerpo social (Deleuze y Guattari, 1998). Cuando los enfrentamientos de la revuelta cesan, las máquinas nómadas y sus tecnologías anarchivistas no se funden simplemente con los regímenes discursivos y sensoriales del orden reestablecido, se ramifican más bien entre sus hendiduras, en los espacios clandestinos de las ciudades, filtrando sus sistemas, hasta que la emergencia impredecible de la revuelta vuelva a hacerlas proliferar a cielo abierto.

De acuerdo con Deleuze (2017), las máquinas o formaciones sociales nómadas se caracterizan por conjurar la concentración de poder que constituye a las máquinas estatales (y a sus respectivas máquinas de archivo), repeliendo sus formas de jerarquización y el despotismo con que sus aparatos instauran el orden social. No se trata, en cualquier caso, de una simple oposición o de una contradicción dialéctica. La vocación jerárquica de la máquina estatal puede colonizar a las agrupaciones nómadas, pero estos últimos también pueden transmutar los dispositivos estatales, generando espacios de horizontalidad y creatividad colectiva que no tributan a los fines jerárquicos del Estado. No hay autarquía de las diferentes formaciones sociales, sino más bien concomitancias, contaminaciones y tensiones. Las máquinas nómadas y los aparatos estatales coexisten entonces en un mismo plano de inmanencia, colisionando y mutando entre sí. Lo mismo puede decirse sobre las máquinas anarchivistas que las formaciones 


\section{Andrés Maximiliano Tello}

sociales nómadas activan: estas no rechazan los registros de los archivos sino la violencia arcóntica de la máquina social que clasifica las huellas de los cuerpos y administra los regímenes discursivos y sensoriales de una sociedad. En ese sentido, las tecnologías anarchivistas de las formaciones sociales nómadas pueden tensionar desde las entrañas a la máquina del archivo estatal, como lo hacen, por ejemplo, las organizaciones que luchan por desclasificar archivos sobre violaciones de los derechos humanos y el terrorismo estatal, los grupos de hackers que filtran información sobre el abuso de poder y la corrupción de las élites políticas y empresariales, los proyectos que construyen archivos disidentes - no arcónticos (sin establecer origen ni mandato sobre los registros) - y tecnologías de código abierto para las formaciones sociales nómadas, y la gran cantidad de colectivos y agrupaciones territoriales que, una vez que el humo de las barricadas se dispersa, siguen trabajando día a día en la construcción de espacios de cuidados y afectos mutuos, auto-organización horizontal e imaginación de otros mundos posibles.

\section{Bibliografía}

Agamben, Giorgio. (2012). “¿Qué es una orden?”. En Teología y lenguaje. Del poder de Dios al juego de los niños. Buenos Aires: Las cuarenta.

Bassa, Jaime. (2019). "Protestas sociales y Constitución: 2019, el inicio de un proceso constituyente". En Revistas Pléyade, Número Especial.

Berardi, Franco. (2015). La fábrica de la infelicidad. Nuevas formas de trabajo y movimiento global. Madrid: Traficantes de sueños.

Bordeleau, Érik. (2018). Foucault anonimato. Cactus: Buenos Aires.

CIPER. (2018). Instagis: el "gran hermano" de las campañas políticas financiado por Corfo. Recuperado en: https://ciperchile.cl/2018/01/03/instagis-el-gran-hermano-de-las-campanaspoliticas-financiado-por-corfo/

Dardot, Pierre. y Laval, Christian. (2013). La nueva razón del mundo. Ensayo sobre la sociedad neoliberal. Barcelona: Gedisa.

Deleuze, Gilles. (2017). Derrames II. Aparatos de estado y axiomática capitalista. Buenos Aires: Cactus. 
Deleuze, Gilles. (1999). Post-scriptum sobre las sociedades de control. En Conversaciones. 19721990 (pp. 277-286). Valencia: Pre-Textos.

Deleuze, Gilles. y Guattari, Felix. (1998). El Anti-Edipo. Capitalismo y esquizofrenia. Barcelona: Paidós, 1998.

Derrida, Jacques. Mal de archivo. Una impresión freudiana. Madrid: Trotta, 1997

Fisher, Mark. (2018). Realismo capitalista. ¿No hay alternativa?. Buenos Aires: Caja Negra.

Foucault, Michel. (1991): "Nuevo orden y control social”, Saber y verdad (Madrid: La Piqueta).

Foucault, Michel. (2009). La arqueología del saber. Madrid: Siglo XXI.

Foucault, Michel. (2010). Nacimiento de la biopolítica. Madrid: Akal.

Jesi, Furio. (2014). Spartakus. Simbología de la revuelta. Buenos Aires: Adriana Hidalgo editora.

La Mura, Florencia. (2019). Quién vigila a quién: las redes sociales en tiempos de crisis. Recuperado en: https://palabrapublica.uchile.cl/2019/11/13/quien-vigila-a-quien-las-redessociales-en-tiempos-de-crisis/

O’Neil, Cathy. (2017). Armas de destrucción matemática. Cómo el Big Data aumenta la desigualdad y amenaza la democracia. Madrid: Capitán Swing.

Orchard, Ximena. (2019). Prensa política: la cámara de eco de las elites. Recuperado en: https://ciperchile.cl/2019/10/29/prensa-politica-la-camara-de-eco-de-las-elites/

Rovira, Guiomar. (2017). Activismo en red y multitudes conectadas. Comunicación y acción en la era de Internet. México D.F.: Universidad Autónoma Metropolitana.

Sepúlveda, Nicolás. (2019). Hackeo a Carabineros en medio de la crisis expone 10.515 archivos: entre ellos hay datos de inteligencia. Recuperado en: https://ciperchile.cl/2019/10/29/hackeo-acarabineros-en-medio-de-la-crisis-expone-10-515-archivos-entre-ellos-hay-datos-de-inteligencia/

Tello, Andrés Maximiliano. (2018). Anarchivismo. Tecnologías políticas del archivo. Buenos Aires: La Cebra. 